\title{
Construction and characterization of peroxisome proliferator-activated receptor-gamma co-activator 1 alpha (PGC-1a over-expressing cell line derived from human hepatocyte carcinoma HepG2 cells)
}

\author{
Aneta Novotna ${ }^{\mathrm{a}}$, Aneta Doricakova ${ }^{\mathrm{a}}$, Petr Pavek ${ }^{\mathrm{b}}$, Zdenek Dvorak $^{\mathrm{a}}$
}

\begin{abstract}
Aims. The aim was develop stable human cell line stable over-expressing transcription co-activator peroxisome proliferator-activated receptor gamma co-activator $1 a(P G C-1 a)$ with restored hepatospecific functions and increased expression of major xenobiotic metabolizing enzymes.

Methods. Six clones of HepG2-PGC-1a and one control clone HepG2-pcDNA3 were isolated and analyzed for secretion of hepatospecific markers, fibrinogen, albumin and alpha1-antitrypsin. Expression levels of protein and mRNA of hepatocyte nuclear factor (HNF4a), pregnane X receptor (PXR) and aryl hydrocarbon receptor (AhR) were determined. We measured basal and ligand inducible expression of CYP1A1 and CYP3A4.

Results. Stably transfected cell line HepG2-PGC-1a derived from HepG2 cells over-expressing PGC-1a displayed increased secretion of fibrinogen, but not albumin or alpha1-antitrypsin compared to parent HepG2 cells. We found increased levels of HNF4a, PXR and AhR proteins but not their mRNAs in HepG2-PGC1 cells. Basal expression of CYP3A4 protein in HepG2-PGC-1 a cells was increased but rifampicin-inducible expression of CYP3A4 protein was lowered in comparison with parent HepG2 cells. Induction of CYP3A4 mRNA varied between $1.3-1.9$ fold in individual clones. Expression of TCDD-inducible CYP1A1 protein was lower in HepG2-PGC-1 a cells than in parent HepG2 cells. Induction of CYP1A1 mRNA by TCDD in HepG2-PGC-1a cells was comparable with that in parent HepG2 cells and ranged between 103 - 198 fold.

Conclusion. Stable expression of PGC-1a in HepG2 cells restores several hepatospecific functions, such as secretion of fibrinogen, expression of HNF4a1 and xenoreceptors PXR and AhR. However, the expression and induction of key drug-metabolizing enzymes (CYP1A1 and CYP3A4) were not improved.
\end{abstract}

Key words: drug metabolism, cell lines, hepatocytes, cytochrome P450

Received: April 10, 2012; Accepted with revision: July 13, 2012; Available online: September 5, 2012 http://dx.doi.org/10.5507/bp.2012.075

${ }^{a}$ Department of Cell Biology and Genetics, Faculty of Science, Palacky University Olomouc, Czech Republic ${ }^{b}$ Department of Pharmacology and Toxicology, Charles University in Prague, Faculty of Pharmacy in Hradec Kralove, Hradec Kralove Corresponding author:Zdenek Dvorak, e-mail:moulin@email.cz

\section{INTRODUCTION}

Altered phenotype and loss of hepatocyte-specific function of human cancer cell lines derived from liver cells is probably the consequence of diminished expression of key transcriptional factors and their co-activators, such as peroxisome proliferator-activated receptor gamma co-activator (PGC-1 $\alpha)$. PGC-1 $\alpha$ was identified as the first member of the PGC-1 family co-activators ${ }^{1}$. Its homologs PGC-1 $\beta$ and PGC-1-related co-activator (PRC) display high similarity in the C-terminus, RNA recognition motif, conserved L1 motif and nuclear receptor interaction domain (L2) in N-terminus ${ }^{2,3}$. PGC-1 co-activators form a complex with several HAT-containing proteins (CBP, p300, SRC-1) at their N-terminal regions or dock the protein mediator complex called TRAP/DRIP on the C-terminal region of PGC- $1 \alpha$ (ref., ${ }^{4,5}$ ). PGC- $1 \alpha$ transcriptional activator displaces the repressor proteins and consequently increases the gene transcription ${ }^{6}$. PGC-1 $\alpha$ plays an important role in the regulation of a wide range of the nuclear receptors such as HNF4 $\alpha$, glucocorticoid receptor, PPAR $\alpha$, and PPAR $\beta$ and others ${ }^{7-9}$. Depending on the cell type, PGC- $1 \alpha$ is regulated in different ways. The major mechanism of PGC- $1 \alpha$ induction is activation of the CAMP signaling pathways through cAMP binding to CREB binding site in proximal promoter of PGC$1 \alpha\left(\right.$ ref. $\left.^{10}\right)$. Another mechanism of PGC- $1 \alpha$ induction involves stimulation of activating transcription factor 2 (ATF2) in brown adipose tissue by cold, or calcium signaling in exercised skeletal muscles and heart ${ }^{11,12}$. The expression of PGC-1 $\alpha$ is controlled by nutritional and hormonal signals as well as by circadian pacemakers ${ }^{13}$. The highest expression was found in tissues with a high density of mitochondria, i.e. heart, kidney, skeletal muscles, brown adipose tissue, liver and brain ${ }^{1,14,15}$. PGC- $1 \alpha$ also plays an important role in adaptive thermogenesis. It is involved in glucose metabolism and maintenance of lipid and energy homeostasis. Fasting induces PGC-1 $\alpha$ expression in adult liver, which leads to activation of the gluconeogenic enzymes phosphoenolpyruvate carboxykinase (PEPCK) and glucose-6-phosphatase through interactions with the transcription factor $\mathrm{HNF} 4 \alpha$ and forkhead box $\mathrm{O} 1$ (FOXO-1) 
(ref. ${ }^{9,16,17}$ ). Moreover, HNF4 $\alpha$ is a key transcriptional factor for maintenance of expression of genes encoding the hepatic xenobiotic-metabolizing enzymes P450s (ref. ${ }^{18,19}$ ). The transactivation effect of PGC- $1 \alpha$ on P450 genes mediated by HNF4 $\alpha$ was corroborated by transfection experiments using MZ-Hep-1 cells that have low levels of HNF4 $\alpha$. Co-transfection of PGC- $1 \alpha$ and HNF4 $\alpha$ increased the levels of CYP2C9, CYP1A1 and CYP1A2, whereas transfection of PGC- $1 \alpha$ or $\mathrm{HNF} 4 \alpha$ alone had no significant effect on $\mathrm{P} 450$ s expression ${ }^{20}$. Compared to primary human hepatocytes, the expression of PGC- $1 \alpha$ in HepG2 is greatly decreased, whereas the expression of HNF4 $\alpha$ is maintained ${ }^{21}$. Transient transfection of HepG2 cells with PGC-1 $\alpha$ significantly increased the expression of CYP2C9, CYP1A1 and CYP1A2 genes, and to a lesser extent the expression of CYP3A4, CYP3A5 and CYP2D6 (ref. ${ }^{20,21}$ ).

In the present study, we describe construction and characterization of a stable cell line derived from HepG2 cells over-expressing transcription co-activator PGC- $1 \alpha$. We observed increased expression of fibrinogen but not albumin or alpha1-antitrypsin in clones over-expressing PGC- $1 \alpha$. The expression of HNF $4 \alpha$, pregnane X receptor (PXR) and aryl hydrocarbon receptor (AhR) proteins but not their mRNAs was increased. Basal and inducible expression of xenobiotic-metabolizing enzymes CYP1A1 and CYP3A4 was not increased compared to parent HepG2 cells. In conclusion, while stable over-expression of PGC- $1 \alpha$ moderately improved hepatospecific functions of HepG2 cells, the resulting cell line did not display higher basal and inducible expression of CYP1A1 and CYP3A4 compared to parent HepG2 cells.

\section{MATERIALS AND METHODS}

\section{Materials}

Oligonucleotide primers used in RT-PCR reactions were from Invitrogen. LightCycler FastStart DNA Master ${ }^{\text {PLUS }}$ SYBR Green I and FuGENE HD transfection reagent were from Roche Diagnostic Corporation (Intes Bohemia, Czech Republic). 2,3,7,8-tetrachlorodibenzop-dioxin (TCDD) was from Ultra Scientific (RI, USA). Rifampicin and DMSO were from Sigma-Aldrich (Prague, Czech Republic). Geneticin (G418) was purchased from Invitrogen (California, USA). All other chemicals were of the highest quality commercially available.

\section{Human hepatoma HepG2 cells}

Human Caucasian hepatocellular carcinoma cells HepG2 (ECACC No. 85011430) were cultured in Dulbecco's modified Eagle's medium (DMEM) supplemented with $10 \%$ fetal calf serum, $100 \mathrm{U} / \mathrm{mL}$ streptomycin, $100 \mu \mathrm{g} / \mathrm{mL}$ penicillin, $4 \mathrm{mM} \mathrm{L}$-glutamine, $1 \%$ non-essential amino acids, and $1 \mathrm{mM}$ sodium pyruvate. Cells were maintained at $37{ }^{\circ} \mathrm{C}$ and $5 \% \mathrm{CO}_{2}$ in a humidified incubator.

\section{Cytotoxicity assay}

HepG2 cells were treated with G418 (400-1400 $\mu \mathrm{g} /$ $\mathrm{mL}$ ) for 1, 2, 3, 6 and 7 days, using 96-well plates. In parallel, the cells were treated with vehicle (DMSO; $0.1 \%$, $\mathrm{v} / \mathrm{v})$ and Triton X-100 (1\%, v/v) to assess the minimal and maximal cell damage, respectively. MTT test was performed using common protocol. Absorbance was measured spectrophotometrically at $540 \mathrm{~nm}$ (TECAN, Schoeller Instruments LLC). The values of $\mathrm{IC}_{50}$ were calculated using data acquired from three independent cell passages.

\section{Transfection of HepG2 cells and the selection protocol}

HepG 2 cells were seeded at a density of $2 \times 10^{6}$ cells in $60 \mathrm{~mm}$ culture dishes in $5 \mathrm{~mL}$ of DMEM culture medium and transfected with pcDNA3-neo- PGC-1 $\alpha$ expressing vector $(2 \mu \mathrm{g})$ (Dr. Ramiro Jover, Unidad de Hepatología Experimental, Centro de Investigación, Hospital La Fe, Valencia, Spain) or empty expressing vector pcDNA3-neo $(2 \mu \mathrm{g})$ using Fugene HD reagent. After $36 \mathrm{~h}$ of incubation, culture medium was replaced by selection medium supplemented with G418 (1.1 mg/mL). The medium was renewed every 3-4 days for a period of 12 weeks, until polyclonal population was selected. Cells were then transferred in $10 \mathrm{~cm}$ culture dishes at density of $500-$ 1000 cells and cultured for an additional 5 weeks under neomycin resistance until small colonies were visible. Six colonies were subcloned into a 48-well tissue culture plate to obtain monoclonal populations. G418 resistant clones were analyzed for secretion of hepatospecific markers and expression of PGC- $1 \alpha$, HNF $4 \alpha$, PXR, AhR, CYP1A1 and CYP3A4. The use of GMO at the Faculty of Science, Palacky University Olomouc was approved by the Czech Ministry of Environment (ref. 91997/ENV/10).

\section{Western blotting and protein detection}

Total protein extract preparation: $3 \times 10^{6}$ cells were washed twice with ice-cold PBS and scraped into $1 \mathrm{~mL}$ of PBS. The suspension was centrifuged (4 500 RPM/5 $\min / 4{ }^{\circ} \mathrm{C}$ ) and the pellet was re-suspended in $170 \mu \mathrm{L}$ of ice-cold lysis buffer (10 mM Hepes pH 7.9; $10 \mathrm{mM} \mathrm{KCl}$; $1.5 \mathrm{mM} \mathrm{MgCl}$; 0.5 mM DTT; anti-protease cocktail, $0.2 \%$ (w/v) sodium dodecylsulfate). The mixture was incubated for $20 \mathrm{~min}$ on ice and then centrifuged (13 $000 \mathrm{RPM} / 13$ $\min / 4{ }^{\circ} \mathrm{C}$. Supernatant was collected and the protein concentration was determined by the Bradford method (Pierce, Rockford, IL.). SDS-PAGE gels ( $8 \%$ ) were run on a Hoeffer apparatus according to the general procedure. Protein transfer onto PVDF membrane was carried out. The membrane was saturated with $5 \%$ non-fat dried milk for $2 \mathrm{~h}$ at room temperature. Blots were probed with primary antibodies against albumin (mouse monoclonal; sc-70340, 1.B.730), fibrinogen (mouse monoclonal; sc65966, GMA-035), $\alpha 1$-antitrypsin (mouse monoclonal; sc-73431, 13702), PGC-1 $\alpha$ (goat polyclonal; sc-8987, H-171), HNF4 $\alpha$ (rabbit polyclonal; sc-8987, H-171), PXR (mouse monoclonal; sc-48340, H-11), AhR (rabbit polyclonal; sc-5579, H-211), CYP1A1 (goat polyclonal; sc-9828, G-18), CYP3A4 (mouse monoclonal; sc-53850, 
HL3) and actin (goat polyclonal; sc-1616, I-19), all purchased from Santa Cruz Biotechnology (Santa Cruz, USA). Chemiluminescence detection was performed using horseradish peroxidase-conjugated secondary antibody and an Amersham (GE Healthcare) ECL kit. Films were scanned and the intensity of the bands was evaluated by densitometry.

mRNA determination and quantitative reverse transcriptase polymerase chain reaction (qRT-PCR)

Total RNA was isolated using TRI Reagent ${ }^{\circledR}$. cDNA was synthesized according to common protocol, using M-MLV Reverse Transcriptase (Invitrogen) and random hexamers (Amersham Biosciences). qRT-PCR was carried out on Light Cycler apparatus (Roche Diagnostic Corporation, Meylan, France). The primers and conditions for determination of CYP1A1, CYP3A4, AhR, PXR, HNF4 $\alpha 1$ and GAPDH mRNAs were described [22]. Primers for PGC-1 $\alpha$ were described [20]. The measurements were performed in duplicate. Gene expression was normalized per glyceraldehyde-3-phosphate dehydrogenase (GAPDH) as a housekeeping gene. Data were processed by the delta-delta method.

\section{Statistical Analyses}

Results were expressed as means \pm standard deviation.

\section{RESULTS}

\section{Cytotoxicity of geneticin}

The dose of geneticin was set at $1.1 \mathrm{mg} / \mathrm{mL}$ of culture medium, based on preliminary cytotoxicity experiments (data not shown).

\section{PGC-1a expression in the stable HepG2 transfectants}

HepG2 cells were transfected with pcDNA3-PGC$1 \alpha$ and control empty plasmid pcDNA3 carrying a neo selection marker conferring resistance to the antibiotic G418 (neo gene). We selected six G418-resistant HepG2PGC-1 $\alpha$ clones and one HepG2-pcDNA3 control clone. We measured the expression of PGC- $1 \alpha$ mRNA and protein in HepG2-PGC-1 $\alpha$, HepG2-pcDNA3 and in parent HepG2 cells. We found no significant difference in the expression levels of PGC- $1 \alpha$ mRNA in HepG2-PGC- $1 \alpha$ cells compared to HepG2-pcDNA3 and parent HepG2 cells. On the other hand, we observed greatly increased

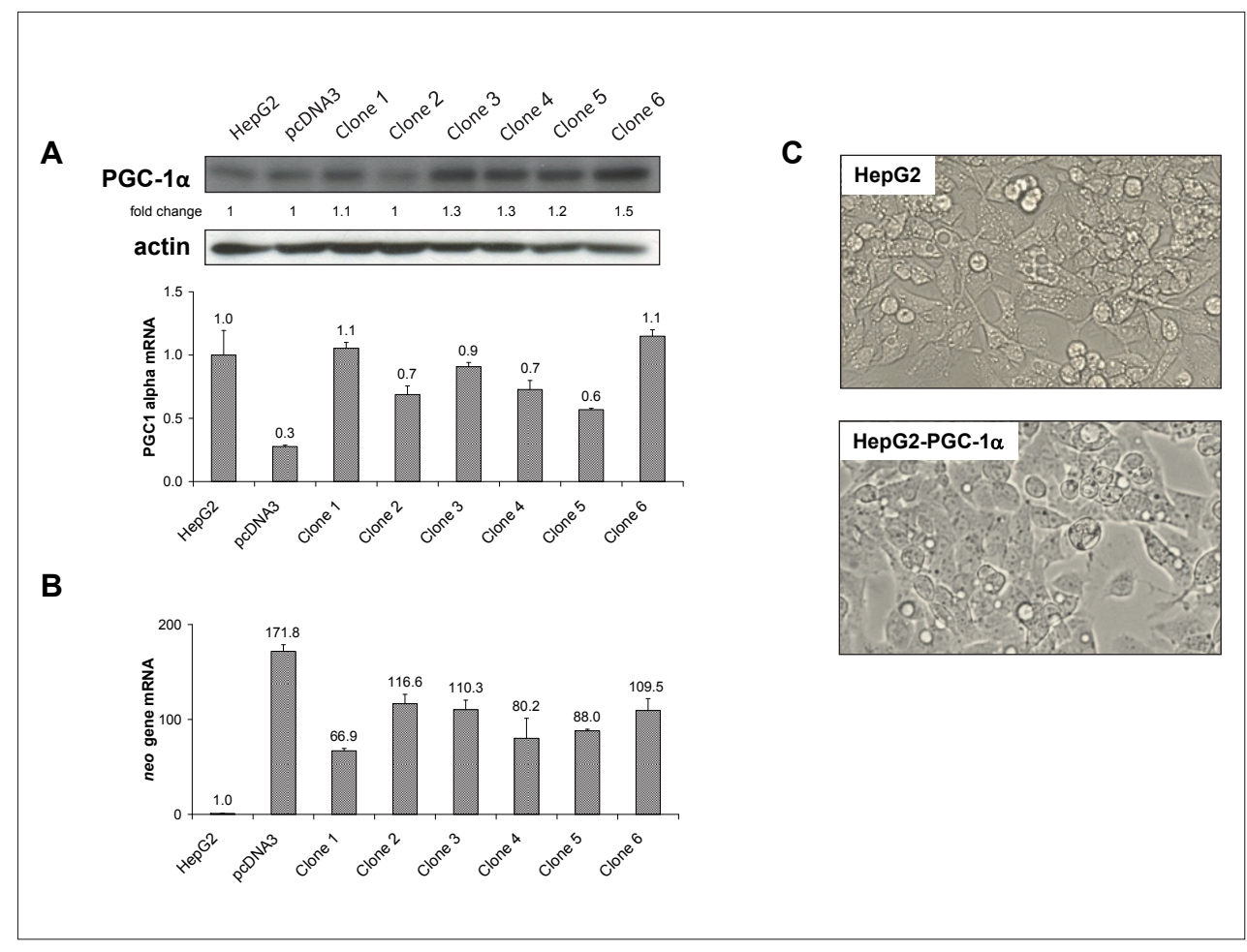

Fig. 1. PGC-1 $\alpha$ expression in the stable G-418 resistant HepG2-PGC-1 $\alpha$ cells. Cells were obtained as described in Materials and Methods section. Panel A: Representative RT-PCR of PGC-1 $\alpha$ mRNA is shown in bar graph; western blot analyses of PGC- $1 \alpha$ protein is above the graph. RT-PCR data are mean \pm SD from duplicate measurements and are expressed as fold induction over the value from parent HepG2 cells. The data were normalized per GAPDH mRNA levels. Similar profiles, both for protein and mRNA, were observed in three independent experiments. Panel B: RT-PCR analysis of Neo resistance gene mRNA in clones of HepG2-PGC-1 $\alpha$ cells. Panel C: Morphology of parent HepG2 and HepG2PGC- $1 \alpha$ stable cell line. The picture shows HepG2 at passage 8 and HepG2-PGC-1 $\alpha$ stable cell line at passage 21. Numbers indicate fold change in protein expression related to the control cells HepG2 determined by densitometry. 


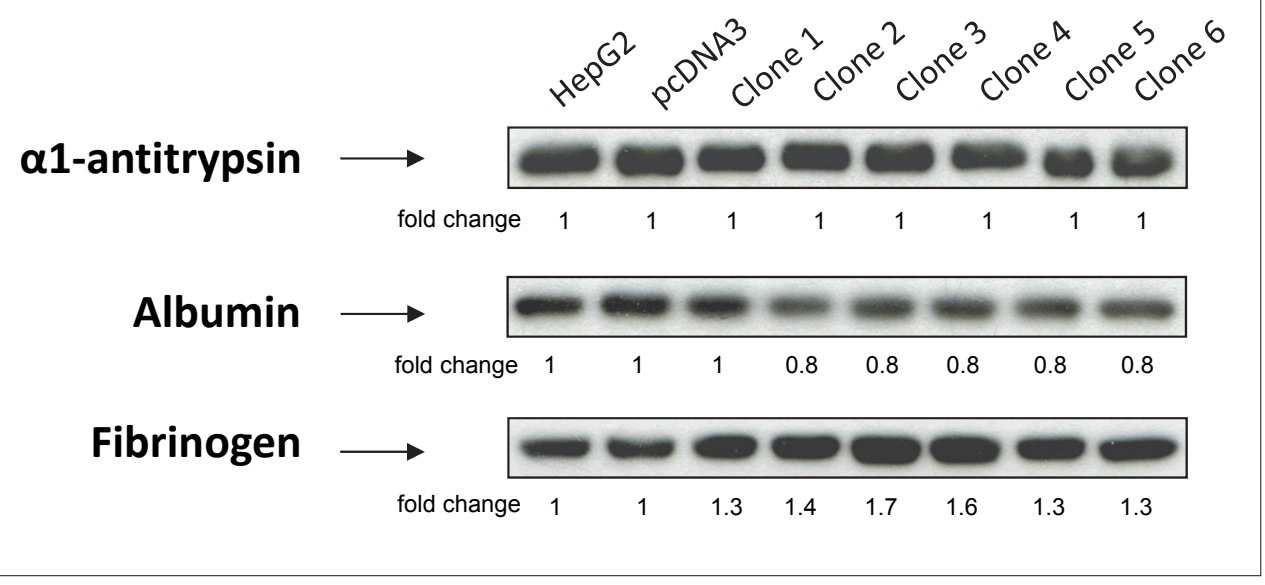

Fig. 2. Secretion of hepatospecific markers in culture of the stable G-418 resistant HepG2PGC1 $\alpha$ cells. HepG2-PGC-1 $\alpha$ cells, HepG2-pcDNA3 cells and parent HepG2 cells were maintained in serum free medium. After $48 \mathrm{~h}$, medium was removed and analyzed for secretion of hepatospecific markers. Representative western blot analyzes $\alpha 1$-antitrypsin, albumin and fibrinogen proteins are showed. Similar profiles were observed in three independent experiments. Numbers indicate fold change in protein expression related to the control cells HepG2 determined by densitometry.

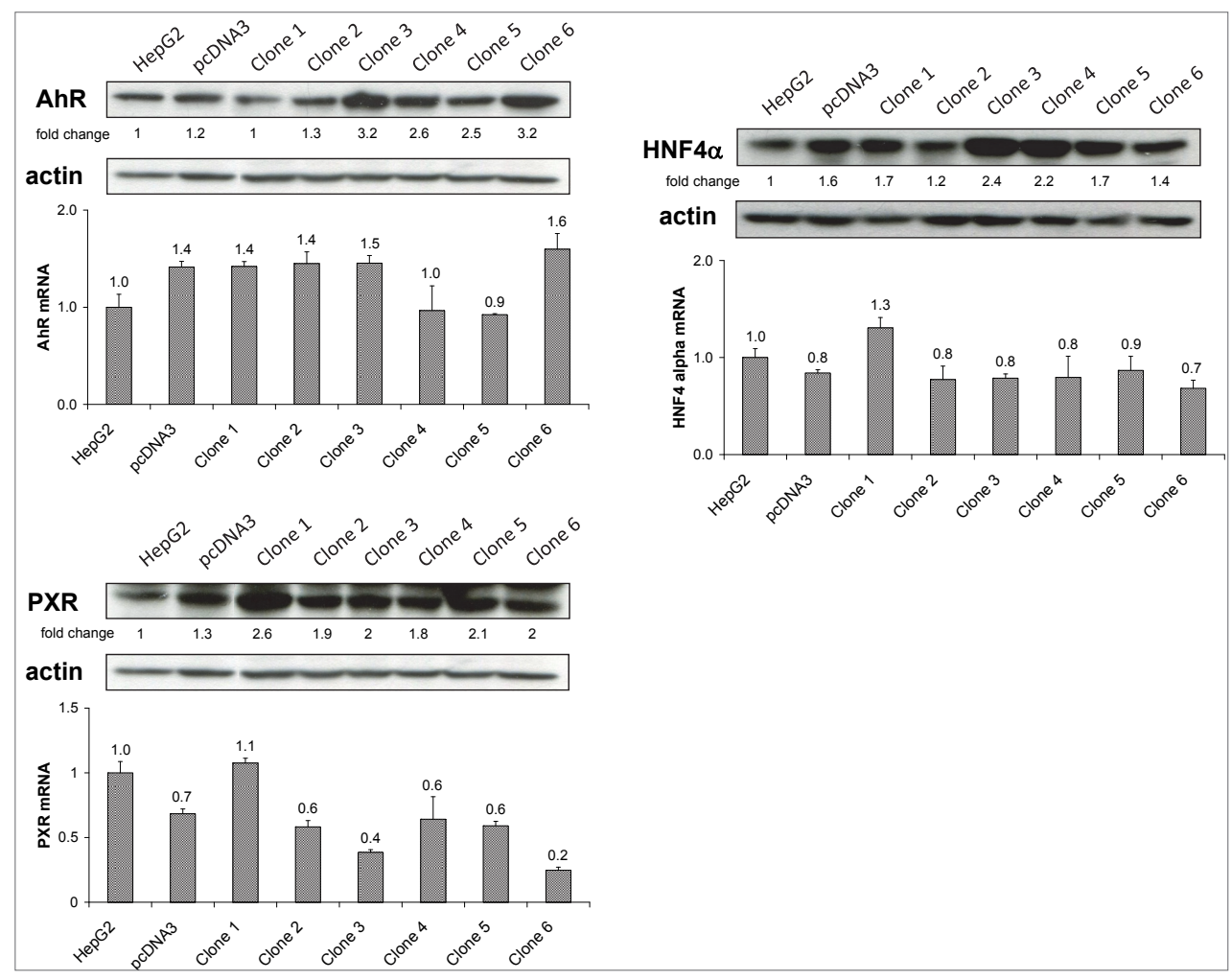

Fig. 3. Expression of AhR, PXR and HNF4 $\alpha$ in the stable G-418 resistant HepG2-PGC$1 \alpha$ cells. Total mRNA and total protein extracts were isolated from HepG2-PGC-1 $\alpha$ cells, HepG2-pcDNA3 cells and parent HepG2 cells. Representative RT-PCR analyses of AhR, PXR and HNF4 $\alpha$ mRNAs are shown in bar graphs; western blots of AhR, PXR and HNF $4 \alpha$ proteins are above individual graphs. Similar profiles were obtained from three independent experiments. RT-PCR data are mean \pm SD from duplicate measurements and are expressed as fold induction over the value of HepG2 parent cells. The data were normalized per GAPDH mRNA levels. Numbers indicate fold change in protein expression related to the control cells HepG2 determined by densitometry. 
PGC-1 $\alpha$ protein level in clones 3, 4, 5 and 6 compared to control HepG2-PGC-1 $\alpha$ and parent HepG2 cells (Fig. 1A). We determined the mRNA expression level of neo gene in HepG2- PGC-1 $\alpha$, HepG2-pcDNA3 and parent HepG 2 cells to verify the stable integration of expressing vector (Fig. 1B). The morphology of HepG2-PGC-1 $\alpha$ cells was slightly different from parent HepG2 cells (Fig. 1C).

\section{Secretion of hepatospecific markers}

We analyzed HepG2-PGC-1 $\alpha$ clones for secretion of hepatospecific markers including $\alpha 1$-antitrypsin, albumin and fibrinogen. The cells were maintained in serum-free medium for $48 \mathrm{~h}$. Secretion proteins in extracellular medium were analyzed by Western immunoblotting. Secretion of fibrinogen was increased in all clones (Fig. 2). The greatest increase was observed in clones 3, 4 and 6, which correlates with the protein level of PGC- $1 \alpha$ and HNF $4 \alpha$ (Fig. 1A and 3). We found no increase in secretion of albumin and $\alpha 1$-antitrypsin in any clone, as compared to HepG2-pcDNA3 and parent HepG2.

\section{Expression of xenoreceptors and transcription factors}

Next, we analyzed the expression of xenoreceptors AhR and PXR, and transcription factor $\mathrm{HNF} 4 \alpha$, the most important regulators of hepatic drug-metabolizing P450s. We found increased expression of HNF4 $\alpha$ protein in all clones (except for clone 2) and in control HepG2pcDNA3 cells as compared to parent HepG2 cells (Fig. $3)$. The greatest increase was detected in clones 3, 4, 5 and 6 and this correlates with PGC- $1 \alpha$ protein level. The expression level of HNF $4 \alpha$ mRNA was moderately decreased in HepG2-pcDNA3 control cells in comparison with parent HepG2 cells. HNF4 $\alpha$ mRNAs level in tested HepG2-PGC- $1 \alpha$ cells ranged between 0.7 fold to 1.3 fold compared to parent HepG2. The level of PXR mRNA in HepG2-pcDNA3 control cells was decreased by approx. $30 \%$ and the levels in clones 1-6 varied between $20 \%$ to $110 \%$ of the PXR level in parent HepG2 cells. On the other hand, the protein level of PXR was increased in all clones as well in control HepG2-pcDNA3 cells compared to parent HepG2 cells (Fig. 3). Expression of AhR mRNAs in the control HepG2-pcDNA3 cells was slightly increased (by approx. 40\%) and in clones 1-6 varied between $90 \%-160 \%$ of the AhR level in parent HepG 2 cells. The AhR protein level in HepG2-pcDNA3 was not altered in comparison with parent HepG2 cells. In contrast, we found major increase in AhR protein levels in clones 3, 4 and 6 and moderate increase in clone 5 (Fig. 3), which correlates with PGC-1 $\alpha$ protein level (Fig. 1A).

\section{Expression of drug-metabolizing enzymes CYP1A1 and CYP3A4}

In the last series of experiments, we measured basal and ligand inducible expression of CYP1A1 and CYP3A4, the most prominent drug-metabolizing cytochromes $\mathrm{P} 450$. HepG2-PGC-1 $\alpha$ cells were treated with rifampicin (RIF; $10 \mu \mathrm{M}$ ), 2,3,7,8-tetrachlorodibenzo- $p$-dioxin (TCDD; 5 $\mathrm{nM}$ ) and vehicle (DMSO; 0.1\% V/V) for $24 \mathrm{~h}$ (mRNA analyzes) and $48 \mathrm{~h}$ (protein analyzes).
Basal expression of CYP3A4 protein in HepG2-PGC$1 \alpha$ cells was markedly increased in all clones, compared to parent HepG2 and control HepG2-pcDNA3 cells. Rifampicin strongly induced CYP3A4 protein in HepG2 and HepG2-pcDNA3 cells. However, found no induction of CYP3A4 protein by rifampicin in HepG2-PGC$1 \alpha$ cells, and the levels of CYP3A4 protein were nearly identical in DMSO- and RIF-treated cells. An apparent loss of CYP3A4 protein induction by RIF was due to the elevated basal levels of CYP3A4 protein in HepG2PGC- $1 \alpha$ cells (Fig. 4A). Induction of CYP3A4 mRNA by RIF ranged from 1.5 to 1.7 fold in parent HepG2 and HepG2-pcDNA3 cells. Basal and RIF-inducible expression of CYP3A4 mRNAs in HepG2-PGC-1 $\alpha$ did not significantly differ from CYP3A4 mRNA expression in parent HepG2 cells (Fig. 4A).

The typical AhR agonist TCDD, induced CYP1A1 mRNA with similar potency in all examined cell lines, i.e., in HepG2 cells (approx. 163 fold), in HepG2-pcDNA3 cells (approx. 150 fold) cells, and in HepG2-PGC-1 $\alpha$ cell clones (from 65 fold to 198 fold in individual clones) (Fig. 4B). No basal level of CYP1A1 protein was found in either cell line under examination. TCDD-inducible expression of CYP1A1 protein was diminished in control cells HepG2-pcDNA3 compared to parent HepG2 cells. The level of CYP1A1 inducible protein was in all clones of HepG2-PGC-1 $\alpha$ cells higher than in control cells HepG2-pcDNA3, but similar to the levels in parent HepG 2 cells. In clone 1 we found stronger induction of CYP1A1 protein than in parent HepG2 but this did not correlate with CYP1A1 mRNA level (Fig. 4B).

\section{DISCUSSION}

Human hepatocyte-derived cancer cell lines have many advantages such as availability, the unlimited lifespan, proliferation in culture, easy cryopreservation in comparison with primary human hepatocytes. For these properties, hepatoma cell lines would be a suitable model for drug-metabolism studies. However, lower biotransformation activity and lack of hepatospecific functions hinders wide use of cancer cell lines for metabolic studies. The loss of hepatic phenotype of cancer cells is at least partly caused by the under-expression of transcription factors or co-activators such as (PGC-1 $\alpha$, SRC-1, SRC$2, \mathrm{c} / \mathrm{EBP}, \mathrm{HNF} 4 \alpha$ ) and others. PGC- $1 \alpha$ plays a role in adaptive thermogenesis, it is involved in activation of gluconegenesis genes in the liver, and it stimulates genes important in mitochondrial function and oxidative metabolism. PGC- $1 \alpha$ activates $\mathrm{P} 450$ genes through co-activation of transcription factor HNF4 $\alpha$ which is a key factor for expression of hepatic drug-metabolizing P450s in mice, in human hepatocytes and for maintaining of hepatospecific functions ${ }^{19}$. Transient co-transfection of MZ-Hep-1 hepatocyte carcinoma cells with PGC-1 $\alpha$ and HNF4 $\alpha$ increased the expression of CYP2C9, CYP1A1 and CYP1A2 (ref. ${ }^{20}$ ). Similarly, transient transfection of HepG2 human hepatoma cells with PGC- $1 \alpha$ increased 

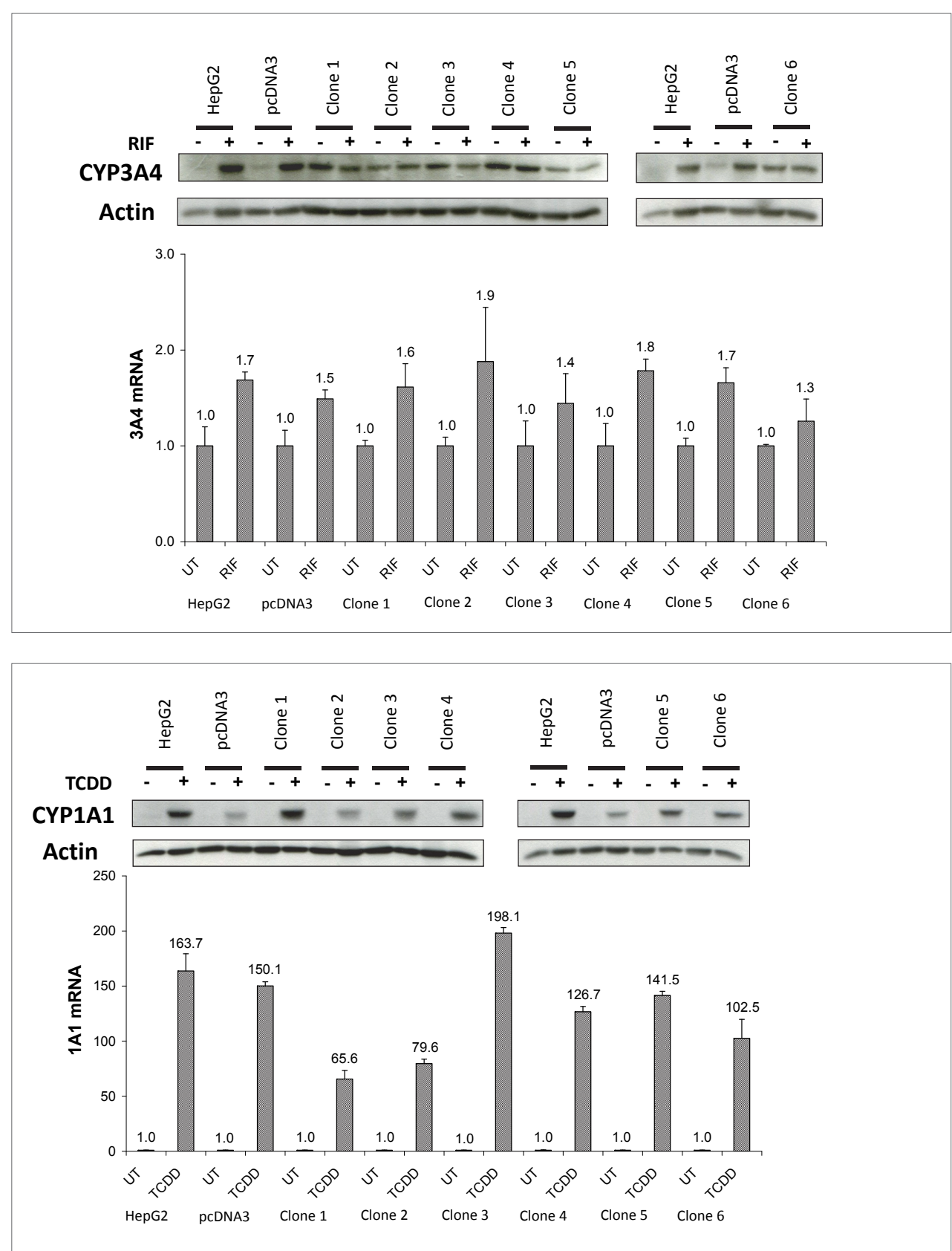

Fig. 4. Expression of CYP1A1 and CYP3A4 in the stable G-418 resistant HepG2-PGC-1 $\alpha$ cells. G418-resistant HepG2-PGC-1 $\alpha$ cells, HepG2-pcDNA3 cells and parent HepG2 cells were treated with rifampicin (RIF; $10 \mu \mathrm{M}$ ), 2,3,7,8- tetrachlorodibenzo-p-dioxin (TCDD; $5 \mathrm{nM}$ ) and vehicle (DMSO; 0.1\% V/V) for $24 \mathrm{~h}$ (mRNA analyzes) and $48 \mathrm{~h}$ (protein analyzes). Representative RT-PCR analyzes and western blots of CYP3A4 (Panel A) and CYP1A1 (Panel B) are showed. Similar profiles were obtained from three independent experiments. RT-PCR data are mean \pm SD from duplicate measurements and are expressed as fold induction over vehicle-treated cells in the each cell type or clone. The data were normalized per GAPDH mRNA levels.

the expression of CYP1A1, CYP1A2, CYP2C9, CYP2D6, CYP3A4 and CYP3A5 genes ${ }^{20}$. Interaction of PGC-1 $\alpha$ with PXR, SRC-1 and HNF4 $\alpha$ is essential for CYP3A4 $\left(\right.$ ref. $\left.{ }^{23,24}\right)$. Another study reported that PGC- $1 \alpha$ activates transcription of CYP2A5 gene through the co-activation of HNF $4 \alpha\left(\right.$ ref. $\left.{ }^{25}\right)$.

In a previous study, we showed that stable over-expression of HNF4 $\alpha$ in HepG2 cells improved some hepato- specific functions including secretion of plasma proteins or increased expression of xenoreceptors PXR and $\mathrm{AhR}^{22}$. Hence, we tested whether stable over-expression of PGC$1 \alpha$ in $\mathrm{HepG} 2$ restores hepatospecific functions. In clones with increased PGC-1 $\alpha$ protein levels, we found strongly increased HNF $4 \alpha$ protein level, which is in accordance with findings of other groups ${ }^{20,23,25}$. Secretion of albumin and proteins involved in the blood coagulation cascade 
are hepatospecific features of the cells. $\mathrm{HNF} 4 \alpha$, regulates the expression of HNF1 (ref. ${ }^{26}$ ), which is involved in the expression of albumin and fibrinogen ${ }^{27,28}$. In addition, a promoter of the $\alpha 1$-antitrypsin gene contains a HNF $4 \alpha$ binding site ${ }^{29}$. We found increased secretion of fibrinogen but not albumin and $\alpha 1$-antitrypsin in all tested clones of HepG2-PGC-1 $\alpha$ cells. However, stable over-expression of HNF $4 \alpha$ in HepG2 increased the secretion of all these three plasma proteins ${ }^{22}$. Xenoreceptors AhR and PXR are the main transcriptional regulators of drug-metabolizing enzymes CYP1A1 and CYP3A4, respectively. We found that over-expression of PGC- $1 \alpha$, and consequently increased expression of HNF $4 \alpha$ protein, positively correlated with increased levels of PXR and AhR proteins in HepG2-PGC1 $\alpha$ clones 3, 4, 5 and 6. However, we found the highest expression of PXR protein in clone 1 which expressed lower levels of PGC-1 $\alpha$ protein than clones 3, 4, 5 and 6. Dioxin-inducible expression of CYP1A1 mRNA and protein was not significantly altered compared to parent HepG2. Basal expression of CYP3A4 protein was increased in HepG2-PGC1 $\alpha$ cells, but rifampicin-inducible expression of CYP3A4 was consequently lost.

In conclusion, this is the first report on the construction of HepG2 cell line stably over-expressing human PGC- $1 \alpha$. The new cell line displayed increased secretion of fibrinogen and higher expression of AhR, PXR and HNF $4 \alpha$ as compared to parent cell line. However, the expression of drug-metabolizing enzymes CYP1A1 and CYP3A4 was not restored, implying that the approach of stable over-expression of hepatospecific transcription factors only partly addressed the problem of the generation of hepatocyte-like cell lines.

\section{ACKNOWLEDGEMENTS}

Our laboratories are supported by the student project PrF 2012-002 of the Palacky University Olomouc and by the grants from the Czech Scientific Agency GACR 303/12/G163, GACR 503/10/0579 and GACR $304 / 10 / 0149$.

\section{CONFLICT OF INTEREST STATEMENT}

Author's conflict of interest disclosure: The authors stated that there are no conflicts of interest regarding the publication of this article.

\section{REFERENCES}

1. Puigserver P, Wu Z, Park CW, Graves R, Wright M, Spiegelman BM. A cold-inducible coactivator of nuclear receptors linked to adaptive thermogenesis. Cell 1998;92(6):829-39.

2. Andersson U, Scarpulla RC. Pgc-1-related coactivator, a novel, seruminducible coactivator of nuclear respiratory factor 1-dependent transcription in mammalian cells. In: Mol Cell Biol 2001;21(11),3738-49.

3. Lin J, Puigserver P, Donovan J, Tarr P, Spiegelman BM. Peroxisome proliferator-activated receptor gamma coactivator 1 beta (PGC1 beta), a novel PGC-1-related transcription coactivator associated with host cell factor. J Biol Chem 2002;277(3):1645-8.
4. Puigserver P, Adelmant G, Wu Z, Fan M, Xu J, O'Malley B, Spiegelman BM. Activation of PPARgamma coactivator-1 through transcription factor docking. Science 1999;286(5443):1368-71.

5. Wallberg AE, Yamamura S, Malik S, Spiegelman BM, Roeder RG. Coordination of p300-mediated chromatin remodeling and TRAP/ mediator function through coactivator PGC-1alpha. Mol Cell 2003;12(5):1137-49.

6. Borgius LJ, Steffensen KR, Gustafsson JA, Treuter E. Glucocorticoid signaling is perturbed by the atypical orphan receptor and corepressor SHP. J Biol Chem 2002;277(51):49761-6.

7. Yoon JC, Puigserver P, Chen G, Donovan J, Wu Z, Rhee J, Adelmant G, Stafford J, Kahn CR, Granner DK, Newgard CB, Spiegelman BM. Control of hepatic gluconeogenesis through the transcriptional coactivator PGC-1. Nature 2001;413(6852):131-8.

8. Shin DJ, Campos JA, Gil G, Osborne TF. PGC-1alpha activates CYP7A1 and bile acid biosynthesis. J Biol Chem 2003;278(50):50047-52.

9. Rhee J, Inoue Y, Yoon JC, Puigserver P, Fan M, Gonzalez FJ, Spiegelman BM. Regulation of hepatic fasting response by PPARgamma coactivator-1alpha (PGC-1): requirement for hepatocyte nuclear factor 4alpha in gluconeogenesis. Proc Natl Acad Sci U S A 2003;100(7):4012-7.

10. Herzig S, Long F, Jhala US, Hedrick S, Quinn R, Bauer A, Rudolph D, Schutz G, Yoon C, Puigserver P, Spiegelman B, Montminy M. CREB regulates hepatic gluconeogenesis through the coactivator PGC-1. Nature 2001;413(6852):179-83.

11. Cao W, Daniel KW, Robidoux J, Puigserver $P$, Medvedev AV, Bai X, Floering LM, Spiegelman BM, Collins S. p38 mitogen-activated protein kinase is the central regulator of cyclic AMP-dependent transcription of the brown fat uncoupling protein 1 gene. Mol Cell Biol 2004;24(7):3057-67.

12. Handschin C, Rhee J, Lin J, Tarr PT, Spiegelman BM. An autoregulatory loop controls peroxisome proliferator-activated receptor gamma coactivator 1alpha expression in muscle. Proc Natl Acad Sci U S A 2003;100(12):7111-6.

13. Spiegelman BM, Heinrich R. Biological control through regulated transcriptional coactivators. Cell 2004;119(2):157-67.

14. Esterbauer $\mathrm{H}$, Oberkofler $\mathrm{H}$, Krempler $\mathrm{F}$, Patsch W. Human peroxisome proliferator activated receptor gamma coactivator 1 (PPARGC1) gene: CDNA sequence, genomic organization, chromosomal localization, and tissue expression. Genomics 1999;62(1):98102.

15. Knutti D, Kaul A, Kralli A. A tissue-specific coactivator of steroid receptors, identified in a functional genetic screen. Mol Cell Biol 2000 20(7):2411-22.

16. Boustead JN, Stadelmaier BT, Eeds AM, Wiebe PO, Svitek CA, Oeser JK, O'Brien RM. Hepatocyte nuclear factor-4 alpha mediates the stimulatory effect of peroxisome proliferator-activated receptor gamma co-activator-1 alpha (PGC-1 alpha) on glucose-6-phosphatase catalytic subunit gene transcription in H4IIE cells. Biochem J 2003;369(Pt 1):17-22.

17. Puigserver P, Rhee J, Donovan J, Walkey CJ, Yoon JC, Oriente F, Kitamura Y, Altomonte J, Dong H, Accili D, Spiegelman BM. Insulinregulated hepatic gluconeogenesis through FOXO1-PGC-1alpha interaction. Nature 2003;423(6939):550-5.

18. Wiwi CA, Gupte M, Waxman DJ. Sexually dimorphic P450 gene expression in liver-specific hepatocyte nuclear factor 4alpha-deficient mice. Mol Endocrinol 2004;18(8):1975-87.

19. Jover R, Bort R, Gomez-Lechon MJ, Castell JV. Cytochrome P450 regulation by hepatocyte nuclear factor 4 in human hepatocytes: $a$ study using adenovirus-mediated antisense targeting. Hepatology 2001;33(3):668-75.

20. Martinez-Jimenez CP, Castell JV, Gomez-Lechon MJ, Jover R. Transcriptional activation of CYP2C9, CYP1A1, and CYP1A2 by hepatocyte nuclear factor 4alpha requires coactivators peroxisomal proliferator activated receptor-gamma coactivator 1 alpha and steroid receptor coactivator 1. Mol Pharmacol 2006;70(5):1681-92.

21. Martinez-Jimenez CP, Gomez-Lechon MJ, Castell JV, Jover R. Underexpressed coactivators PGC1 alpha and SRC1 impair hepatocyte nuclear factor 4 alpha function and promote dedifferentiation in human hepatoma cells. J Biol Chem 2006;281(40):29840-9.

22. Novotna A, Doricakova A, Vrzal R, Pavek P, Dvorak Z. Construction and characterization of hepatocyte nuclear factor HNF4alpha1 overexpressing cell line derived from human hepatoma HepG2 cells. Eur J Pharmacol 2011;669(1-3):45-50.

23. Li T and Chiang JY. Rifampicin induction of CYP3A4 requires pregnane $X$ receptor cross talk with hepatocyte nuclear factor 4 alpha and 
coactivators, and suppression of small heterodimer partner gene expression. Drug Metab Dispos 2006;34(5):756-64.

24. Matsumura K, Saito T, Takahashi Y, Ozeki T, Kiyotani K, Fujieda M, Yamazaki $\mathrm{H}$, Kunitoh $\mathrm{H}$, Kamataki T. Identification of a novel polymorphic enhancer of the human CYP3A4 gene. Mol Pharmaco 2004;65(2):326-34.

25. Arpiainen S, Jarvenpaa SM, Manninen A, Viitala P, Lang MA, Pelkonen $\mathrm{O}$, Hakkola J. Coactivator PGC-1alpha regulates the fasting inducible xenobiotic-metabolizing enzyme CYP2A5 in mouse primary hepatocytes. Toxicol Appl Pharmacol 2008;232(1):135-41.

26. Yamagata K, Furuta H, Oda N, Kaisaki PJ, Menzel S, Cox NJ, Fajans SS, Signorini S, Stoffel M, Bell Gl. Mutations in the hepatocyte nu- clear factor-4alpha gene in maturity-onset diabetes of the young (MODY1). Nature 1996;384(6608):458-60.

27. Maire P, Wuarin J, Schibler U. The role of cis-acting promoter elements in tissue-specific albumin gene expression. Science 1989;244(4902):343-6.

28. Tronche F, Ringeisen F, Blumenfeld M, Yaniv M, Pontoglio M. Analysis of the distribution of binding sites for a tissue-specific transcription factor in the vertebrate genome. J Mol Biol 1997;266(2):231-45.

29. Monaci P, Nicosia A , Cortese R. Two different liver-specific factors stimulate in vitro transcription from the human alpha 1-antitrypsin promoter. Embo J 1988;7(7):2075-87. 